\title{
ANOCHECE EN LA INDIA: UNA ROAD MOVIE VITAL
}

\author{
Alba Zarzuela Lucea \\ Universidad Complutense de Madrid \\ albazarlu@hotmail.com
}

\section{RESUMEN}

Chema Rodríguez ha conseguido que Anochece en la India nos atrape y emocione. Esta película canta a la vida, paradójicamente, y a la superación personal. Los espectadores se pueden ver movidos a reflexiones personales, a recorridos y viajes interiores. Todo ello lo consigue con un gran trabajo, muy arriesgado y poético, cuidando la historia y los aspectos que le dan vida en la pantalla. Nominada en los premios Goya al mejor guion adaptado, Anochece en la India se basa en la novela Anochece en Katmandú, escrita por el propio director del filme. Este artículo pretende acercarse tanto al rodaje como a la historia y su trasfondo.

Palabras clave: discapacidad, dependencia, dignidad, migración rumana, road movie.

\section{CHEMA RODRÍGUEZ: CREADOR, GUIONISTA Y DIRECTOR}

Ver cualquier pieza audiovisual de Chema Rodríguez es viajar sin dar un paso. Ver cualquier historia escrita y dirigida por él, es un viaje tanto físico como espiritual de unos personajes que reflexionan y realizan una aventura interior para redescubrirse a sí mismos, de la misma manera que consigue que suceda con cada espectador. El cineasta logra trasladarnos al lugar donde viven, donde respiran, disfrutan o sufren esos personajes. Sin duda, es éste un director de personajes y de paisajes.

A Chema Rodríguez le respalda la dirección y el guion de tres largometrajes documentales como son Estrellas de la Línea, El abrazo de los peces y Coyote, además de ser guionista en La Gran Final. Su primer filme, Estrellas de la Línea, obtuvo tres premios ÍCARO como Mejor Película Centroamericana, Mejor Director y Mejor Montaje de 2006. Además, es productor de Estrellas de la Línea, y guionista, director y productor de los cortometrajes Amor callejero y Triste borracha. Además de participar en numerosos documentales emitidos en TVE y en diversas operadoras internacionales, como Sahel, la frontera herida, El barco de Ulises, La llamada de África, Vivir en el agua o Latidos.

Anochece en la India se basa en la novela Anochece en Katmandú, escrita por el propio director del filme. Anochece en la India fue nominada en los pasados premios Goya al mejor guion adaptado, realizado por Chema Rodríguez, David Planell y Pablo Burgués. Otros libros escritos por el director de este largometraje de ficción son El diente de la ballena, Colores de África y La Ruta de la Seda. Pero, sobre todo, se puede decir que Chema Rodríguez es un documentalista que se embarca aquí en su primera ficción: Anochece en la India. 
El propio director afirmó en una entrevista para el programa Días de cine que el viaje es solo una excusa para contar una historia sobre la imposibilidad de recuperar el tiempo perdido. La película es un viaje emocional de dos personajes que tienen un tour de force brutal.

El director ha escogido unos paisajes maravillosos para acompañar a los protagonistas, conoce perfectamente los lugares por donde transcurre la vida de Ricardo, y eso queda patente en cada plano del filme.

\section{LORENZO DEL AMO: EL PROTAGONISTA REAL}

Lorenzo del Amo es el Ricardo de la realidad, el hombre en el que se basa la historia. En palabras del director, "Lorenzo es un hippie que en los años sesenta, setenta llevaba otros hippies a la India en una furgoneta, que en los años ochenta tuvo un accidente en el Río Níger y se quedó parapléjico y vive en una silla de ruedas desde entonces».

Empezó viajando por Europa haciendo autostop. Fue la primera persona en España en organizar un viaje de aventuras, en los años setenta. Decidió, junto a cuatro amigos, dar la vuelta al mundo, partiendo desde Berlín, pero ese primer gran viaje se truncó.

Lorenzo decidió que la India era el mejor lugar para comenzar la vuelta al mundo. En la primera etapa viajó hasta Estambul haciendo autostop y ahí conoció a una chica. El viaje de Lorenzo fue más largo por ella.

En alguna ocasión, en el filme se menciona a esa chica tan misteriosa (Ilamada Gadhali en la ficción, Adinda en la realidad), la cual podría ser la causa de que el protagonista, Ricardo, decida viajar una última vez, y ésta definitivamente a la India, como se deja ver al comienzo de la película a través de una proyección.

Unos años más tarde volvió a intentar dar la vuelta al mundo y una vez más permaneció varios meses en la India.

Su accidente lo sufrió en la siguiente aventura: recorrer África en tractor. El viaje le ocupó quince meses. Parte de ese recorrido, desde Madrid hasta llegar al continente africano, tuvo que hacerlo a escondidas por diferentes razones.

En 2014, Lorenzo del Amo recibió el Premio Miembro de Honor por la Sociedad Geográfica Española. Falleció la noche de San Juan de 2015.

Chema Rodríguez conoció a Lorenzo del Amo hace casi veinte años, cuando el director del filme era guía turístico y el protagonista de su historia era uno de los organizadores de viajes a África. De esa relación nació una enorme amistad y Lorenzo le contó a Chema que su sueño era volver algún día a la India. Chema se fue a la India en su lugar, junto con el productor de la película, buscando los orígenes de la historia. De ese viaje surgió el libro Anochece en Katmandú. Más adelante se imaginó el personaje de Ricardo en la piel de Juan Diego y este personaje tomó vida propia, como explica el propio director. Y con este bagaje a sus espaldas Juan Diego interpreta a Ricardo.

\section{PERSONAJES Y ACTORES}

Chema Rodríguez pensó desde que estaba escribiendo el guion en Juan Diego para interpretar a Ricardo. El protagonista es un tipo a ratos encantador, a ratos muy gruñón; transmite ternura y animadversión. La discapacidad le permite ser en algunos momentos de la película canalla, e incluso cruel. Esta característica le da al personaje ciertas licencias que Dana le permite. 
El personaje de Ricardo se nos presenta así, como un tipo huraño. Se deja claro que ha sufrido mucho en la vida, pero que se aprovecha de su discapacidad para manipular, en ocasiones, a Dana. A lo largo de la película se muestra que en el fondo es buena persona. Esa bondad se comienza a ver durante el viaje; en él, el espectador aprecia los diferentes matices del personaje de Ricardo.

La idea que se transmite en esta película sobre la discapacidad por una parte es de dependencia, física y emocional; incluso es Ricardo el que le dice a Dana que cargue con él. Y por otra, se intenta transmitir todo lo contrario mediante la actitud y los hechos de Ricardo, que aparece como un ser completamente independiente.

En una carta que escribió el propio actor explicaba que este papel lo había aceptado por el aprendizaje que iba a vivir de la mano de Ricardo, en su camino, en su viaje hacia la muerte.

Juan Diego interpreta a la perfección esa dualidad. Llena a este personaje de humanidad y autenticidad. Lo engrandece. Hace que se vuelva irresistible para el espectador. Se llevó el Premio Biznaga de Plata al Mejor Actor en el Festival de Málaga de 2014 por interpretar a Ricardo. Muestra verdad en cada palabra, en cada gesto, y te introduce en la historia desde su comienzo. Solamente escuchando la voz del personaje, éste se define.

Por su parte, Dana es mucho más que una asistente o cuidadora rumana, es alguien que está huyendo de sí misma y que ha encontrado una burbuja que le permite aislarse del resto del mundo, también de sus numerosos problemas. En el viaje intentará resolverlos y curar sus cicatrices. Es una mujer oscura y a la vez tiene una luz que resplandece. Clara Voda ha reflejado todo ello de manera espléndida en el filme.

El director ya vio esa capacidad de esta actriz en varias películas rumanas protagonizadas por Clara en los últimos años, por ello entre otras cualidades la eligió.

Ambos personajes tienen su cara y su cruz. Ambos muestran su lado decadente y su claridad. Esa doble cara es la que se deja ver durante el viaje. Éste va haciendo mella en su carácter, que poco a poco se va suavizando. Aunque al comienzo de la película parece que ambos carecen de estos matices.

Esta dualidad les convierte en redondos, hace que los personajes enganchen a los espectadores. Éstos empatizan con Ricardo y Dana; a pesar de las diferencias y la distancia, hace que compartan sus deseos e ilusiones y que sufran con sus desgracias.

Podríamos hablar del viaje como otro personaje que hace que todo encaje. Puesto que la película es una road movie, los espectadores van de la mano de los personajes, aunque no siempre es así.

Ambos actores bordan la interpretación de sus personajes y aunque no lo estuvieron, creo, en mi humilde opinión, que tendrían que haber estado nominados a los premios Goya de 2015. Clara Voda mereció ser nominada a mejor actriz revelación, mientras que Juan Diego debería haber optado, como mínimo, a mejor actor, sin desmerecer en ningún momento al resto de intérpretes que optaban a ese premio.

\section{TEMÁTICAS}

Se ha mencionado ya la influencia de la discapacidad en el personaje de Ricardo. Evidentemente, él no sería el mismo si no fuese en una silla de ruedas, pero la asunción de esa discapacidad y cómo influye en su carácter es lo que evoluciona a lo largo de la vida del protagonista, no solo durante el tiempo en el que transcurre el filme sino a través de lo que recuerda o lo que le cuenta a Dana. 
El suicidio y el miedo a morir es otro tema recurrente en la película; de hecho, el viaje es un viaje hacia la muerte. Está presente desde el comienzo, el espectador es consciente de cómo va a terminar la película muy poco tiempo después de que haya empezado. Pero los personajes no hablan de ello hasta que llegan a su destino. Y es allí, en la India, donde, ante el inminente final, se quitan las máscaras completamente y muestran esas facetas de la personalidad que habíamos ido adivinando. Donde muestran su lado más sensible y auténtico, ante un tema tan delicado y difícil de tratar en el cine. No obstante, la película acaba dando un giro y sorprendiendo al espectador.

Otro tema central es el amor. Se reflexiona sobre el límite entre el amor y la amistad. La dualidad de los personajes, mencionada en diferentes ocasiones, aparece unida también a la evolución del amor entre ambos. No cabría imaginar en las primeras escenas, de enfrentamiento entre ellos, que los protagonistas se conviertan en cómplices conforme avanza el viaje. Lo que al inicio parece rechazo, desprecio, indiferencia, acaba convirtiéndose en protección, amor y deseo.

Los estereotipos y el rechazo a ellos surgen también a lo largo de la historia. En torno a dos aspectos, la discapacidad y el extranjero. Curiosamente, a Ricardo no le gusta que le prejuzguen por ir en una silla de ruedas. De hecho en las entrevistas de trabajo para elegir cuidador, se burla de ellos y se parapeta tras su carácter agrio y displicente porque no le gusta que lo compadezcan por su situación. Pero él mismo también trata a Dana con aires de superioridad, presuponiendo que lo que necesita básicamente es dinero, antes de que ella le muestre su realidad y su pasado.

Incardinados con estos temas principales, tienen cabida en esta historia aspectos como la sinceridad, la cobardía y la valentía, la paciencia, la honradez, la responsabilidad y el respeto. Es una historia de personas y de personajes, por ello muchos aspectos del ser humano se muestran en la película.

\section{LENGUAJES DE LA PELÍCULA}

El lenguaje empleado en el filme tiene doble significado. El director juega en diferentes ocasiones con las metáforas, por ejemplo el cartel de Se vende del revés. Éstas, a veces, dan ese toque de humor amargo y en otras ocasiones, el drama pasa a primer plano; de hecho, esto sucede durante la mayor parte de la película. Son las metáforas sobre la vida las que aportan emociones y hacen que la historia llegue al espectador

El tono de la película es oscuro, acorde con lo que ofrecen los personajes; sobre todo al comienzo del film. El uso de la luz es magnífico. Destacan los planos donde los claroscuros inundan la pantalla y se complementan con las características de los personajes. Podríamos decir que con la fotografía se adelanta al espectador los diversos matices de los personajes que se mostrarán más adelante. El propio director afirma que la película acaba sobreexpuesta, refiriéndose a la fotografía; sin embargo, esto se podría ampliar a lo que ocurre a los personajes. Es un viaje de la oscuridad a la luz en palabras de su director y, en mi opinión, esto abarca todos los aspectos.

La música también acompaña y aporta ritmo a determinadas escenas que sirven de transición. Unas transiciones necesarias.

El montaje se aborda con gran maestría: juega con el orden de los planos, con su alternancia. El montaje, a veces, aporta un ritmo más intenso para que los diálogos brillen más. La manera en la que se enseña al espectador el recorrido que hace desde España a través de distintos países europeos mostrándolo con los sonidos de la radio es sublime. 


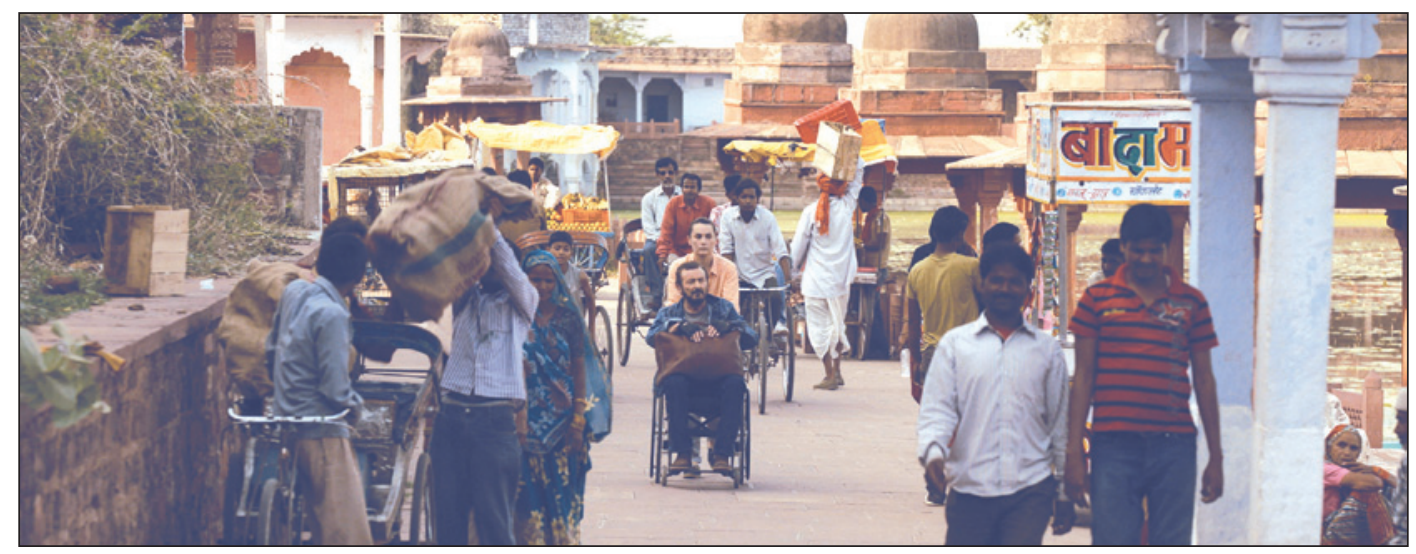

Anochece en la India (Chema Rodríguez, 2014).

Mediante la imagen Chema Rodríguez consigue decir mucho; sin emplear la palabra el personaje de Dana nos lo muestra todo, y también enseña a Ricardo de lo que huye y el por qué de todo su mundo.

Los diálogos en los que se juega y combina el rumano con el español e, incluso el inglés, a veces rozan el absurdo. Este es un elemento para introducir el humor en la película y así provocar sonrisas en la sala.

Otro recurso que emplea el director es el de mirar a la cámara y hablarle directamente a ella. Esta es otra forma de llegar al espectador. Aunque éste sepa las reglas del juego, y que no le hablan a él directamente sino al personaje que está en el lugar de la cámara, aun así se involucra más en la historia.

En mi opinión, el viaje que el espectador hace a la India lo realiza de la mano de los personajes; es decir, Chema Rodríguez no se detiene en mostrarnos que estamos en los diferentes países por los que pasa enseñándonos sus monumentos o sus costumbres. Lo muestra a través de detalles, y eso nos permite que la cámara no se separe de los protagonistas y sean ellos lo verdaderamente importante en el filme.

El final también es muy arriesgado, no sigue el Modo de Representación Institucional por el que se suelen regir las películas que siguen el modelo hollywoodiense. Chema Rodríguez busca terminar, como ha hecho durante toda la película, huyendo de los convencionalismos, y con su no final feliz vuelve a descolocarnos y dejarnos con un sabor de boca especial: esperábamos un final distinto.

\section{RUMANÍA EN ANOCHECE EN LA INDIA}

Algunos de los estereotipos que se mencionan en el film están relacionados con Rumanía y éstos vienen de la mano del personaje de Ricardo. Al comienzo del viaje, el protagonista dice a Dana que por ser una mujer rumana no puede quedarse en la casa ella sola, piensa que está con él solo porque necesita el dinero y no se ha planteado que pueda haber otra causa.

Cuando Ricardo llega a Rumanía empieza a descubrir a la verdadera Dana. Comienza a conocer quién es, por qué actúa de la manera en que lo hace, y cuál es su pasado; descubre su realidad. Y la misma está muy alejada de lo que él había pensado.

Se da cuenta de que todos sus prejuicios sobre ella son falsos. Cuando llega a su casa le sorprende lo grande que es, esperaba pobreza y soledad. Seguramente porque es rumana, pero Dana ni es pobre ni está sola. 


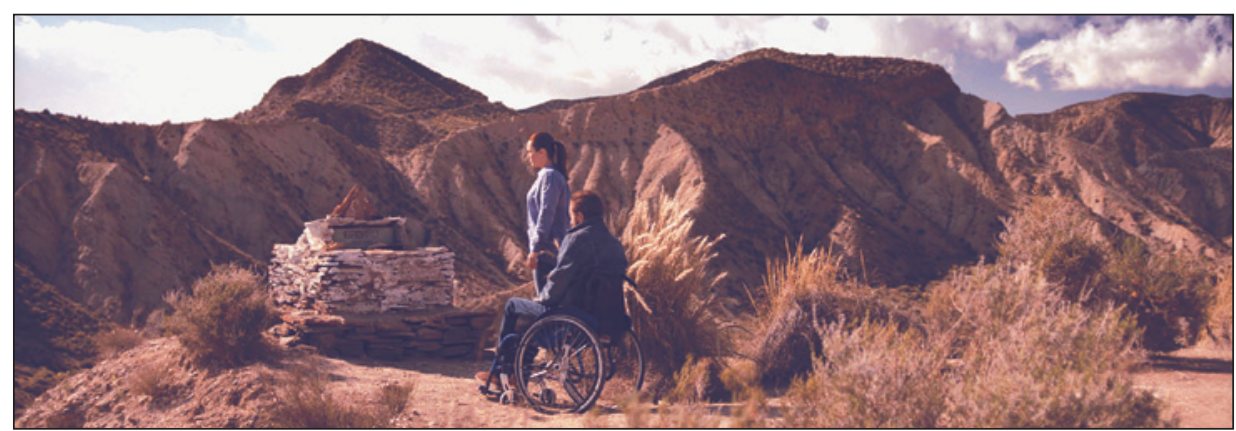

Anochece en la India (Chema Rodríguez, 2014).

Los países que recorren en Anochece en la India no se muestran. Únicamente el origen, el destino y Rumanía. Con pinceladas breves se consigue dar una idea de cómo vive la familia de la protagonista y romper con los estereotipos: una casa grande y bonita sin Internet y un sobrino universitario nos dan una visión de este país.

\section{CONCLUSIONES}

Se ha intentado analizar Anochece en la India desde algunos aspectos técnicos y narrativos: argumento, interpretación, fotografía e iluminación o montaje. Pero un filme es una manifestación artística y estética que nos atrapa al verlo por causas que la mayoría de los espectadores desconoce, pero que el director ha estudiado con minuciosidad.

Chema Rodríguez ha conseguido que Anochece en la India nos atrape y emocione. Esta es una película que canta a la vida, paradójicamente, y a la superación personal. Los espectadores pueden verse movidos a reflexiones personales, a recorridos y viajes interiores.

El cineasta lo consigue con un gran trabajo, muy arriesgado y poético, cuidando la historia y todos los aspectos que le dan vida en la pantalla.

\section{WEBGRAFÍA}

«Adaptación del libro + Lorenzo del Amo», Anochece en la India, https://www.youtube.com/ watch?v=S1Xafnmb_hY

"Clara Voda», Anochece en la India, https://www.youtube.com/watch?v=smfh3X1MgPU

Días de cine, 11 de abril de 2014: http://www.rtve.es/alacarta/videos/dias-de-cine/anocheceindia/2501694/

Discurso Lorenzo del Amo al recibir el Premio Miembro de Honor SGE 2014: https://www.youtube.com/watch?v=vz63v9q7MEc

Entrevista a Lorenzo del Amo, http://www.efetur.com/entrevista/lorenzo-del-amo/

"Juan Diego», Anochece en la India, https://www.youtube.com/watch?v=sria39LdrVs

«La Script», Cadena SER, 10 de abril de 2014, http://cadenaser.com/programa/2014/04/10/ audios/1397085436_660215.html

«La Script», Cadena SER. 11 de abril de 2014, http://cadenaser.com/programa/2014/04/11/ la_script/1397188801_011247.html

«La Script», Cadena SER. 12 de abril de 2014, http://play.cadenaser.com/audio/20140412 csrcsrcul_17.Aes/

«Rodar con pasión», Anochece en la India, https://www.youtube.com/watch?v=25VV6u8eaQU Web oficial, Anochece en la India, http://www.anocheceenlaindia.com/la-pelicula/los-actores/ Web oficial, Chema Rodríguez, http://www.chemarodriguez.es/cine?id=1 